\title{
QUALIDADE FISIOLÓGICA DE SEMENTES DE Ocimum selloi BENTH. SOB CONDIÇÕES DE LUZ, TEMPERATURA E TEMPO DE ARMAZENAMENTO
}

\author{
Physiological quality of Ocimum selloi Benth. seeds under conditions \\ of light, temperature and storage time
}

\author{
Larissa Corrêa do Bomfim Costa ${ }^{1}$, José Eduardo Brasil Pereira Pinto², \\ Suzan Kelly Vilela Bertolucci' ${ }^{2}$, Renato Mendes Guimarães ${ }^{2}$
}

\begin{abstract}
RESUMO
O atroveran ou elixir-paregórico (Ocimum selloi Benth.) é uma espécie aromática nativa do Brasil, produtora de óleo essencial rico em metil-chavicol. Neste trabalho, objetivou-se avaliar a influência da temperatura, luz e tempo de armazenamento em diferentes ambientes sobre a germinação e o vigor de sementes de $O$. selloi. Inicialmente, testou-se o efeito da presença e ausência de luz branca sob fotoperíodo de 12 horas para determinar o fotoblastismo das sementes em diferentes temperaturas $\left(20,25,30\right.$ e $\left.35^{\circ} \mathrm{C}\right)$. Em seguida, testou-se a germinação e emergência no armazenamento sob duas temperaturas (ambiente e câmara fria) aos $0,2,4,6,810$ e 12 meses de armazenamento. A espécie foi classificada como fotoblástica neutra, apresentando germinação em ampla faixa de temperatura $\left(20 \mathrm{a} 30^{\circ} \mathrm{C}\right)$. A germinação das sementes manteve-se por doze meses de armazenamento em câmara fria e à temperatura ambiente, entretanto, o vigor decresce a partir de seis meses em armazenamento sob temperatura ambiente.
\end{abstract}

Termos para indexação: Planta medicinal, germinação, armazenamento, longevidade.

\begin{abstract}
"Atroveran" or "elixir-paregórico" (Ocimum selloi Benth.) is a Brazilian species that produces an essential oil rich in methyl chavicol. This work aimed to evaluate the influence of light, temperature and time of storage in different environments on the germination and vigor of $O$. selloi seeds. We initially tested the influence of presence and absence of white light in a 12-hour photoperiod to determine the photoblastism of the seeds under different temperatures $\left(20,25,30\right.$ and $\left.35^{\circ} \mathrm{C}\right)$. The physiological quality of seeds conserved under two temperatures (room temperature and cold chamber) was tested at 0, 2, 4, 6, 810 and 12 months of storage. The species was classified as neutral photoblastic with germination at a wide temperature range $\left(20^{\circ} \mathrm{C}-30^{\circ} \mathrm{C}\right)$. Germination was maintained for twelve months of storage in cold chamber at room temperature, but the vigor was reduced in seeds kept at room temperature after the sixth month of storage.
\end{abstract}

Index terms: Medicinal plant, germination, storage, longevity.

(Recebido em 22 de setembro de 2008 e aprovado em 14 de maio de 2009)

\section{INTRODUÇÃO}

A família Lamiaceae possui grande importância econômica, em razão da sua abundância em espécies aromáticas, destacando-se o gênero Ocimum, com várias plantas denominadas popularmente de manjericão ou alfavaca que se destacam pelo seu aroma e uso medicinal. Ocimum selloi Benth. Conhecida, vulgarmente, como elixirparegórico, anis ou alfavaquinha é um subarbusto perene, aromático, ereto, ramificado, nativo do sul do Brasil, cultivada em jardins e hortas domésticas pela sua utilidade condimentar e medicinal. Multiplica-se tanto por sementes, quanto por estacas, sendo seu desenvolvimento favorecido em terrenos bem drenados à meia-sombra. Suas folhas e inflorescências frescas são consideradas digestivo-estomacais e hepático-biliares, sendo empregadas para eliminar gases intestinais, contra gastrite, vômitos, tosse, bronquite, gripe, febre e resfriado (Lorenzi \& Matos, 2002).

A exploração de plantas medicinais da flora nativa, por meio do extrativismo tem levado a reduções drásticas das suas populações naturais, tanto pelo processo predatório, quanto pelo desconhecimento dos mecanismos de perpetuação dessas espécies. O cultivo das plantas medicinais envolve a possibilidade de domesticação da espécie a ser utilizada, implicando no domínio tecnológico de todas as etapas de desenvolvimento da espécie, desde o conhecimento da forma de propagação, adaptação ao ambiente de cultivo, forma de crescimento, senescência, etc (Reis \& Mariot, 2000).

Considerando a importância de $O$. selloi como uma fonte potencial de óleo essencial rico em estragol (Martins,

1Universidade Estadual de Santa Cruz/UESC - Departamento de Ciências Biológicas - Rodovia Ilhéus Itabuna - km 16 - $45662-900$ - Ilhéus, BA larissa@uesc.br

2Universidade Federal de Lavras /UFLA - Departamento de Agricultura/DAG - Lavras, MG 
1998), a espécie vem sendo caracterizada com relação aos aspectos morfológicos (Martins, 1998), fitoquímicos (Moraes et al., 2002) e produtivos (Costa et al., 2007b). Quanto às suas formas de propagação, estudos comprovam a viabilidade da produção de mudas por meio de estacas (Costa et al., 2007a), mas ainda não há relatos sobre características da propagação sexuada dessa espécie como germinação, vigor e longevidade. A capacidade de uma semente manter sua qualidade durante o armazenamento, depende da longevidade inerente à espécie e da sua qualidade inicial, mas as condições de armazenamento podem modificar o seu potencial de conservação (Carvalho \& Pinho, 1997).

Conduziu-se este trabalho, com o objetivo de avaliar a influência da temperatura, da luz e do tempo de armazenamento em diferentes ambientes sobre a germinação e o vigor de sementes de $O$. selloi.

\section{MATERIAL E MÉTODOS}

Sementes de $O$. selloi foram coletadas em Lavras (MG), em setembro de 2006, a partir de dez plantas matrizes (depósito Herbário ESAL n ${ }^{\circ}$ 7474), previamente cultivadas em casa de vegetação.

Inicialmente, determinou-se o grau de umidade pelo método da estufa a $105^{\circ} \mathrm{C}$, por 24 horas e a massa de mil sementes com a utilização de oito subamostras de 100 sementes, seguindo as recomendações das Regras para Análise de Sementes (RAS) (Brasil, 1992).

\section{Efeito da luz e temperatura}

Foram realizados dois experimentos, sendo o primeiro delineado para avaliar a influência da temperatura e condição de luz sobre a germinação das sementes de $O$. selloi, em esquema fatorial $4 \mathrm{X} 2$.

Caixas plásticas transparentes (gerbox), contendo substrato de germinação tipo mata-borrão e 50 sementes, foram mantidas em germinadores tipo BOD, regulada a temperaturas constantes de $20,25,30$ e $35^{\circ} \mathrm{C}$ e fotoperíodo de 12 horas. As avaliações e contagens das sementes germinadas (protrusão da radícula) foram feitas aos 2, 4, 6 , 8 e 10 dias após a semeadura. Para verificar a germinação na ausência de luz (escuro), as caixas transparentes foram envoltas em papel de alumínio para vedar totalmente a passagem de luz e as contagens foram feitas em câmara escura, sob luz verde, nos mesmos períodos.

\section{Efeito do tempo de armazenamento e temperatura de conservação}

Utilizando-se a melhor temperatura para germinação do experimento I, montou-se o experimento II para avaliar o efeito do tempo de armazenamento e da temperatura de conservação sobre a germinação das sementes e emergência das plântulas em um esquema fatorial $7 \mathrm{X} 2$, constando de sete períodos de armazenamento das sementes ( $0,2,4,6,810$ e 12 meses), em duas temperaturas: ambiente $\left(25^{\circ} \mathrm{C} \pm 2\right)$ e câmara fria a $\left(4^{\circ} \mathrm{C} \pm 2\right)$. As sementes submetidas aos tratamentos permaneceram embaladas em frascos de vidro envoltos por papel alumínio.

$\mathrm{O}$ experimento foi instalado em germinador de sala com temperatura constante e iluminação artificial, mantida com lâmpadas fluorescentes em regime de 16 horas claro e 8 horas escuro. As avaliações de germinação e emergência foram realizadas com quatro repetições de 50 sementes cada uma realizada diariamente, por 10 dias, em cada época de armazenamento.

Para a germinação, as sementes foram distribuídas sobre substrato de germinação, tipo mata-borrão, colocado dentro de caixas plásticas transparentes, umedecidas com um volume de água 2,5 vezes a sua massa, enquanto que para emergência, as sementes foram distribuídas sobre substrato formado por areia e solo na proporção de 2:1, colocado dentro de caixas plásticas transparentes e umedecido com um volume equivalente a $70 \%$ da sua capacidade de campo.

O delineamento experimental foi inteiramente casualizado e os resultados obtidos foram submetidos à análise de variância com comparação de médias pelo teste F a 5\% de probabilidade para a temperatura de conservação e análise de regressão para o IVG no tempo de armazenamento.

\section{RESULTADOS E DISCUSSÃO}

As sementes de $O$. selloi apresentaram massa de mil sementes de 1,34 g a 7,3\% de umidade, característica de sementes ortodoxas que, normalmente, são pequenas e leves. As sementes umedecidas apresentaram a formação de uma camada mucilaginosa (Figura 1).

\section{Efeito da luz e temperatura}

As sementes mantidas sob diferentes temperaturas na presença e ausência de luz apresentaram respostas diferenciadas quanto à germinação, havendo interação entre os fatores estudados.

As porcentagens de germinação na presença e ausência de luz nas temperaturas de 20,25 e $30^{\circ} \mathrm{C}$ não diferiram entre si e foram, significativamente, superiores aos valores obtidos a $35^{\circ} \mathrm{C}$ (Tabela 1 ). Essa indiferença quanto à presença de luz permite classificar as sementes de $O$. sello $i$ como fotoblásticas neutras. O efeito do estímulo luminoso pode ser variável em sementes de espécies silvestres, como 
Tabebuia aurea (Cabral et al., 2003) e Hyptis marrubioides (Sales, 2006) que apresentaram-se indiferentes à luz para germinação, enquanto que Baccharis trimera, Eupatorium laevigatum e Mikania cordifolia são consideradas fotoblásicas positivas (Ferreira et al., 2001) .

A capacidade de germinação na faixa de temperatura de 20 a $30^{\circ} \mathrm{C}$ também encontrada em Tabebuia aurea (Cabral et al., 2003) e Eupatorium laevigatum (Ferreira et al., 2001), pode representar um caráter adaptativo que aumenta a capacidade de estabelecimento da espécie em campo e as suas chances de sobrevivência, além de ser uma característica interessante, quando se deseja exploração econômica da espécie.

A temperatura de $35^{\circ} \mathrm{C}$ pode ter induzido uma dormência secundária, ou mesmo causado a morte das sementes, uma vez que a germinabilidade nesta temperatura foi de $38 \%$ na presença de luz e nula na ausência de luz (Tabela 1).

$\mathrm{O}$ vigor das sementes, avaliado pelo índice de velocidade de germinação, também apresentou comportamentos distintos em função dos níveis de luz e temperatura, sendo que o maior valor foi obtido a $25^{\circ} \mathrm{C}$ na presença de luz (Tabela 1), condição esta aproveitada para o estabelecimento do experimento seguinte.

\section{Efeito do tempo de armazenamento e temperatura de conservação}

No segundo experimento, não houve interação significativa entre o tempo de armazenamento e a temperatura de conservação sobre a germinação das sementes, tendo ocorrido efeito apenas dos fatores isoladamente. A porcentagem de germinação de $O$. selloi manteve-se elevada durante todo o período de armazenamento, sendo significativamente maior para as sementes mantidas em condição refrigerada (99\%) do que para aquelas armazenadas à temperatura ambiente (96\%) pelo teste $\mathrm{F}$ a $5 \%$ de probabilidade. Geralmente, a longevidade das sementes ortodoxas é aumentada quando são conservadas com baixo grau de umidade e baixa temperatura (Popinigis, 1977).

A germinação das sementes armazenadas nos dois ambientes foi rápida, ocorrendo protrusão da radícula, no terceiro dia após a semeadura, com o máximo de germinação entre o terceiro e o quinto dia, terminando aos sete dias nas sementes mantidas em temperatura ambiente e aos seis dias para aquelas armazenadas em condição refrigerada (Figura 2).

O índice de velocidade de germinação das sementes apresentou um ajuste quadrático com tendência crescente ao longo do tempo para as sementes mantidas em condição refrigerada, superando a viabilidade daquelas armazenadas em temperatura ambiente, a partir do sexto mês de armazenamento (Figura 3). Nos dois tratamentos, a viabilidade foi mantida durante todo o período experimental, indicando que essas condições são suficientes para a conservação das sementes pelo menos por doze meses. Da mesma forma, sementes de erva-detouro (Tridax procumbens L.) armazenadas a baixas temperaturas (câmara fria e congelador), mantiveram a sua viabilidade durante todo o período experimental (730 dias de armazenamento), quando comparadas com as sementes que permaneceram no solo ou em armazém convencional (Guimarães et al., 2004). A preservação do potencial de armazenamento das sementes de aroeira (Myracrodruon urundeuva) também foi mantida por 12 meses, quando foram armazenadas em câmara fria independentemente da embalagem utilizada (Teófilo et al., 2004).

Quanto à emergência da parte aérea, o tratamento controle (sem armazenamento) foi o que demorou mais para iniciar e se prolongou por mais tempo. Nas duas condições de armazenamento, a emergência iniciou no quinto dia,

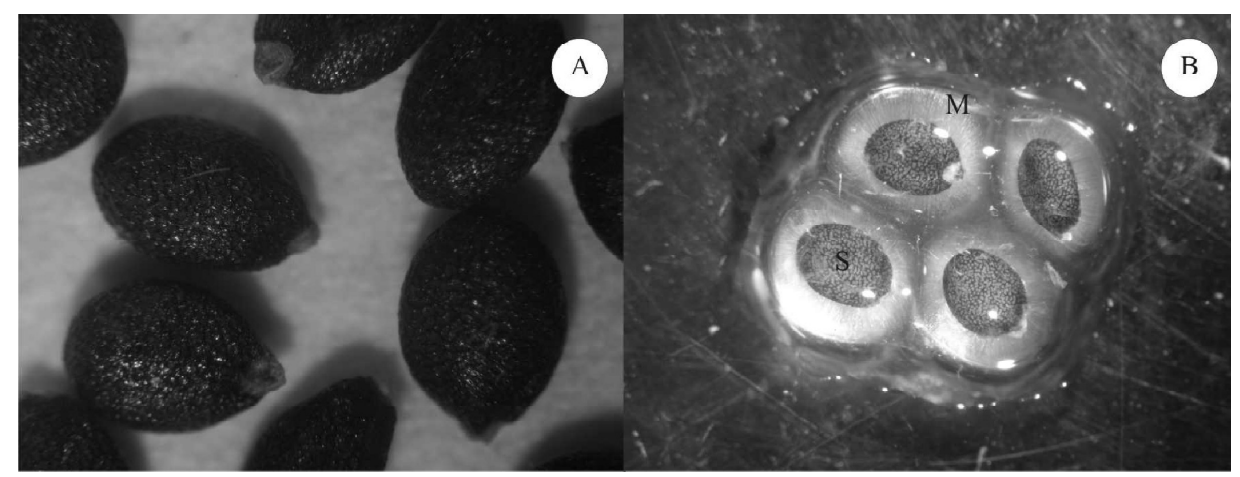

Figura 1 - Sementes de Ocimum selloi secas (A) e hidratadas (B), envoltas por camada de mucilagem (M). 
sendo antecipada para o quarto dia a partir do décimo mês de armazenamento. O máximo de emergência foi observado entre o quinto e o sexto dia, encerrando aos sete dias (Figura 4).

A porcentagem e o índice de velocidade de emergência apresentaram tendência de incremento ao longo do período de armazenamento para as sementes mantidas em condição refrigerada, ao contrário das sementes conservadas em temperatura ambiente (Figura 5). No armazenamento, temperaturas maiores provocam aceleração da atividade respiratória das sementes e de fungos que as acompanham, reduzindo a sua longevidade (Popinigis, 1977; Carvalho \& Pinho, 1997).

Tabela 1 -Efeito da temperatura e luz sobre a porcentagem de germinação e o índice de velocidade de germinação (IVG) de sementes de Ocimum selloi.

\begin{tabular}{|c|c|c|c|c|}
\hline \multirow[b]{2}{*}{ Temperatura $\left({ }^{\circ} \mathrm{C}\right)$} & \multicolumn{2}{|c|}{ Germinação (\%) } & \multicolumn{2}{|c|}{ IVG } \\
\hline & Com luz & Sem luz & Com luz & Sem luz \\
\hline 20 & 96 aA & $98 \mathrm{aA}$ & $7,15 \mathrm{aB}$ & 7,22 aA \\
\hline 25 & $99 \mathrm{aA}$ & $94 \mathrm{aA}$ & $10,45 \mathrm{aA}$ & 8,07 bA \\
\hline 30 & 98 aA & 94 aA & $8,32 \mathrm{aB}$ & 7,92 aA \\
\hline 35 & $38 \mathrm{aB}$ & $00 \mathrm{bB}$ & $2,27 \mathrm{aC}$ & $0,00 \mathrm{bB}$ \\
\hline
\end{tabular}

Médias seguidas de mesma letra minúscula nas linhas e maiúscula nas colunas não diferem significativamente entre si pelo teste de Tukey $(\mathrm{p}<0,05)$.
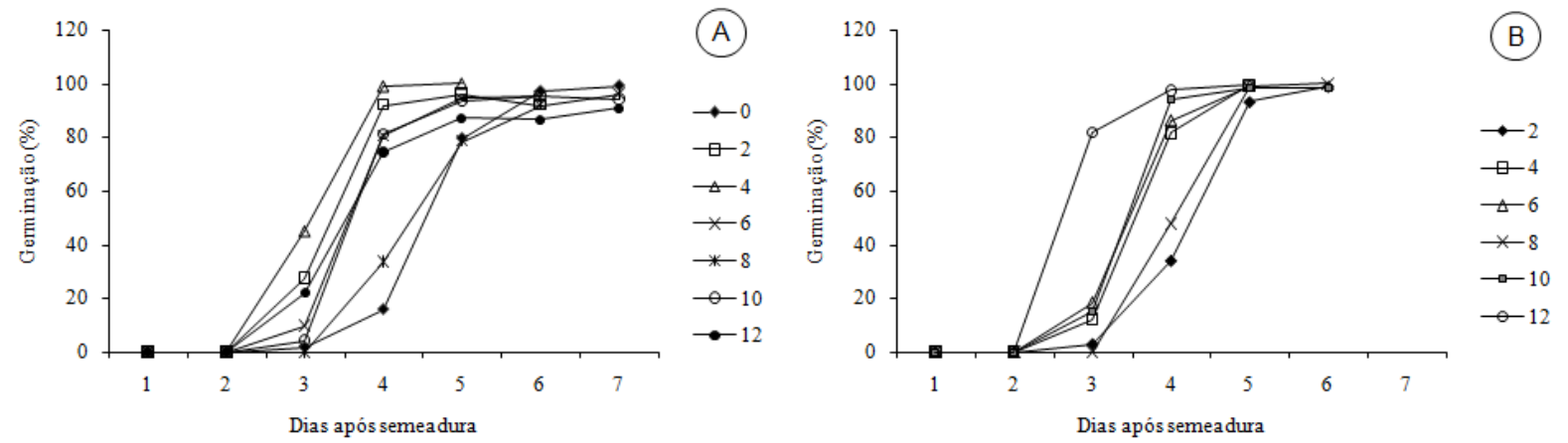

Figura 2 - Germinação acumulada de sementes de Ocimum selloi, após diferentes períodos de armazenamento em temperatura ambiente (A) e refrigerada (B).

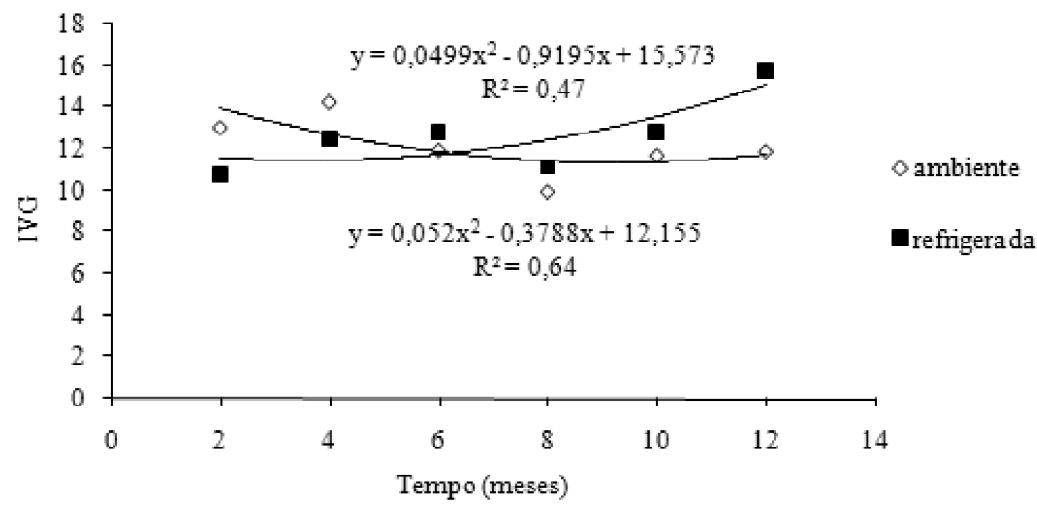

Figura 3 - Efeito do tempo de armazenamento e da temperatura de conservação sobre o índice de velocidade de germinação (IVG) de Ocimum selloi armazenados em temperatura ambiente e refrigerada. 

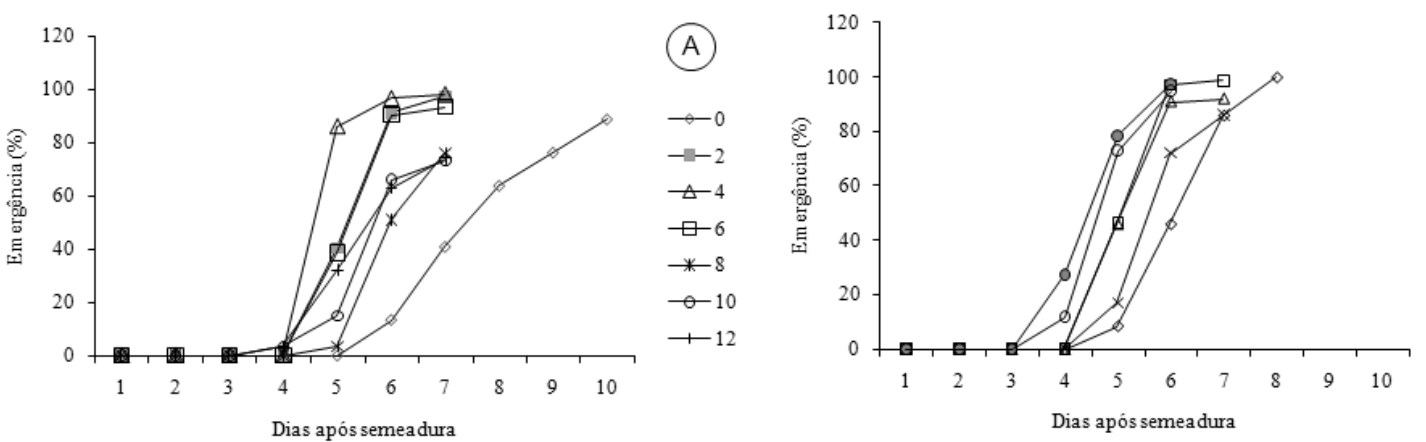

Figura 4 -Emergência acumulada das plântulas formadas de sementes de Ocimum selloi, após diferentes períodos de armazenamento em temperatura ambiente (A) e refrigerada (B).
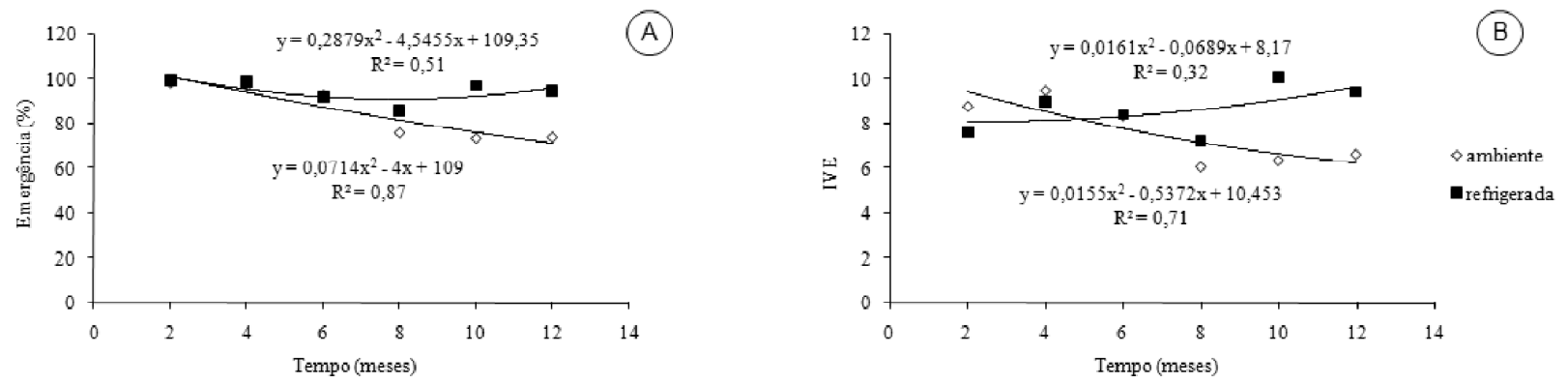

Figura 5 - Efeito do tempo de armazenamento e da temperatura de conservação sobre a emergência (A) e o índice de velocidade de emergência (IVE) (B) de Ocimum selloi.

\section{CONCLUSÃO}

As sementes de $O$. selloi são fotoblásticas neutras com capacidade de germinação em ampla faixa de temperatura $\left(20\right.$ a $\left.30^{\circ} \mathrm{C}\right)$. A germinação das sementes manteve-se por doze meses de armazenamento em câmara fria e à temperatura ambiente, entretanto, o vigor decresce a partir de seis meses em armazenamento sob temperatura ambiente.

\section{AGRADECIMENTO}

Ao Conselho Nacional de Desenvolvimento Científico e Tecnológico (CNPq) e à Fundação de Amparo à Pesquisa de Minas Gerais (FAPEMIG) pelo apoio financeiro.

\section{REFERÊNCIAS BIBLIOGRÁFICAS}

BRASIL. Ministério da Agricultura e Reforma Agrária. Regras para análise de sementes. Brasília: SNDA/ DNDV/CLAV, 1992. 365p.

CABRAL, E.L.; BARBOSA, D.C.A.; SIMABUKURO, E.A. Armazenamento e germinação de sementes de
Tabebuia aurea (Manso) Benth. \& Hook. F. ex. S. Moore. Acta Botanica Brasilica, Porto Alegre, v.17, n.4, p.609-617, 2003.

CARVALHO, M.L.M.; PINHO, E.V.R. von. Armazenamento de sementes. Lavras: UFLA/FAEPE, 1997. 67p.

COSTA, L.C.B.; PINTO, J.E.B.P.; BERTOLUCCI, S.K.V. Comprimento da estaca e tipo de substrato na propagação vegetativa de atroveran. Ciência Rural, Santa Maria, v.37, n.4, p.1157-1160, 2007a.

COSTA, L.C.B.; PINTO, J.E.B.P.; BERTOLUCCI, S.K.V.; CARDOSO, M.G. Produção de biomassa e óleo essencial de elixir-paregórico em função do corte das inflorescências e épocas de colheita. Horticultura Brasileira, Brasília, v.25, p.175-179, 2007b.

FERREIRA, A.G.; CASSOL. B.; ROSA, S.G.T.; SILVEIRA, T.S.; STIVAL, A.L.; SILVA, A.A. Germinação de sementes de Asteraceae nativas no Rio Grande do Sul, Brasil: germinação de sementes de Asteraceae nativas no Rio Grande do Sul, Brasil. Acta Botanica Brasilica, São Paulo, v.15, n.2, p.231-242, 2001. 
GUIMARÃES, S.C.; SOUZA, I.F.; PINHO, E.V.R.V. Viabilidade de sementes de erva-de-touro sob diferentes condições de armazenamento. Planta Daninha, Viçosa, v.22, n.2, p.231-238, 2004.

LORENZI, H.; MATOS, F.J.A. Plantas medicinais no Brasil: nativas e exóticas. Nova Odessa: Instituto Plantarum, 2003. 512p.

MARTINS, E.R. Estudos em Ocimum selloi Benth: isoenzimas, morfologia e óleo essencial. In: MING, L.C.; SCHEFFER, M.C.; CORRÊA JÚNIOR, C.; BARROS, I.B.I.; MATTOS, J.K.A. Plantas medicinais e aromáticas condimentares: avanços na pesquisa agronômica. Botucatu: UNESP, 1998. v.2, p.97-126.

MORAES, L.A.A.S.; FACANALI, R.; MARQUES, M.O.M.; MING, L.C.; MEIRELES, M.A.A. Phytochemical caracterization of essential oil from Ocimum selloi. Anais da Academia Brasileira de Ciências, Rio de Janeiro, v.74, n.1, p.183-186, 2002.
POPINIGIS, F. Fisiologia da semente. Brasília: Agiplan, 1977. 289p.

REIS, M.S.; MARIOT, A. Diversidade natural e aspectos agronômicos de plantas medicinais. In: SIMÕES, C.M. de O. et al. Farmacognosia: da planta ao medicamento. 2.ed. Porto Alegre: UFRGS; Florianópolis: UFSC, 2000. p.39-60.

SALES, J.F. Germinação de sementes, crescimento da planta e composição química do óleo essencial de Hyptis marrubioides Epl., Lamiaceae. 2006. 80f. Tese (Doutorado Fitotecnia)-Universidade Federal de Lavras, Lavras, 2006.

TEÓFILO, E.M.; SILVA, S.O.; BEZERRA, A.M.E.; MEDEIROS FILHO, S.; SILVA, F.D.B. Qualidade fisiológica de sementes de aroeira (Myracrodruon urundeuva Alemão) em função do tipo de embalagem, ambiente e tempo de armazenamento. Revista Ciência Agronômica, Fortaleza, v.35, n.2, p.371-376, 2004. 